INTERNATIONAL JOURNAL OF RESEARCHES IN BIOSCIENCES, AGRICULTURE \& TECHNOLOGY (C) VISHWASHANTI MULTIPURPOSE SOCIETY (Global Peace Multipurpose Society) R. No. MH-659/13(N) www.vmsindia.org

\title{
EVALUATION OF ANTIMICROBIAL RESISTANCE PATTERNS OF STAPHYLOCOCCUS AUREUS IN TERTIARY CARE CENTERS, CHANDRAPUR (M.S.), INDIA
}

\author{
Jungari, M. J. \\ PGTD of Microbiology, RTMNU, Nagpur (M. S.), India \\ Corresponding author email: jungarimonali06@gmail.com
}

\begin{abstract}
Although prevalence rate of MRSA strains are increasing world widely. Very few studies are available of hospital acquired MRSA prevalence in Chandrapur region of Maharashtra, India. The purpose of this study is to determine the prevalence rate of MRSA in tertiary care hospital of Chandrapur .From Government district hospitals, Chandrapur the total 94 clinical samples were collected from different source and 78 samples were positive for $S$. aureus. Out of these 50 clinical samples were positive for coagulase test. The prevalence rate of methicillin resistance among 50 coagulase positive $S$. aureus isolates on disc diffusion was $58.00 \%$. More than $50 \%$ of S. aureus strains were found as resistance to most of the antibiotics. Vancomycin, amikacin, gentamycin, chloramphenicol and nrofloxacin were shown less resistance. The regular surveillance of hospital acquired infection and implementation of strict antibiotic policy may be helpful for reducing the prevalence of MRSA infection.
\end{abstract}

Keywords: MRSA, antibiotics, S.aureus

\section{INTRODUCTION:}

Staphylococcus aureus has long been recognized as a major pathogen of hospital acquired infections. Over the last few decades, Methicillin resistant Staphylococcus aureus (MRSA) strains have become endemic in hospitals worldwide. Antibiotic resistant pathogen constitutes an important and growing threat to public health. . In healthy individuals, the carrier rate of $S$. aureus range between $15 \%$ to $35 \%$ with a risk of $38 \%$ of individuals developing infection followed by a further $3 \%$ risk of infection when colonized with Methicillin susceptible Staphylococcus aureus (MSSA)12. Some groups of individuals are more susceptible to $S$. aureus colonization than others including health-care workers, nursing home inhabitants, prison inmates, military recruits and children's ${ }^{3-4}$. Healthcare associated Methicillin-resistant Staphylococcus aureus (MRSA) is a major cause of nosocomial infection with significant attribute morbidity and mortality in addition to pronounced healthcare cost. Many hospital struggles with increasing amount of MRSA which are multi-resistant against all $\beta$-lactum antibiotics. Methicillin resistance in Staphylococcus is due to acquisition of the mecA gene which encodes the low affinity penicillin binding protein $2 \mathrm{a}$.
The mortality rate from a $S$. aureus infection was as high as $82 \%$ in the pre-antibiotics era but fell dramatically after the introduction of penicillin in market in 19475. Presently, about $80 \%$ S. aureus are reported resistant to penicillin. Resistance to methicillin in S. aureus is associated with the resistance to multiple drug resistance (MDR). MRSA with MDR leaves a limited choice of antibiotics for treatment, and cause difficult to treat infections ${ }^{6}$. This in turn not only affects the rates of morbidity and mortality, but also the hospital cost, and thus the economy of a country ${ }^{7}$. This study aims to determine prevalence rate of methicillin resistant $S$. aureus strains and antimicrobial susceptibility pattern against locally used antibiotics.

\section{MATERIALS AND METHODS:}

The specimens were collected during six months period from July 2014 to December 2014. Routine clinical microbiology specimens (Pus, burn Wound swab and Sputum) were selected during the study period from Government hospitals Chandrapur by using sterile cotton swabs and sterile containers (from HiMedia) from different age groups of individual. The total 94 clinical samples were collected from different source. Isolation and antimicrobial 
susceptibility were done as per CLSI guidelines ${ }^{8}$.

\section{RESULTS AND DISCUSSION:}

From Government district hospitals, Chandrapur the total 94 clinical samples were collected from different source and 78 samples were positive for $S$. aureus. Out of these 50 clinical samples were positive for coagulase test (Table 1).

\subsection{Antimicrobial susceptibility patterns} by Disc diffusion method

All clinical $S$. aureus samples were investigated by Disk diffusion method. Those isolates were shown resistant on disk diffusion which was further reconfirmed on Oxacillin resistant screen agar base (ORSAB) with $2 \mathrm{mg} / \mathrm{L}$ oxacillin $50000 \mathrm{U} / \mathrm{L}$ polymyxin $\mathrm{B}$ and $5.5 \% \mathrm{NaCl}$ as suggested by CLSI standards 8 .

3.2 Overall resistant patterns of $S$. aureus

A total of viable strains of coagulase positive S. aureus from Chandrapur region were tested for antimicrobial susceptibility by disc diffusion. The antibiotic susceptibility test by disc diffusion was done on each isolate by using 12 antibiotics; Oxacillin (OX), Amikacin (AK), Tetracycline (TE), Erythromycin (E), Gentamycin (GN), Methicillin (MET), Chloramphenicol (C), Penicillin (P), Tobramycin (TB), Norfloxacin (NX), Nitrofurantoin (NF) and Vancomycin (V). The resistance pattern of each antibiotic tested was found as follows; oxacillin 29 (58\%), Amikacin 12 (24\%), Tetracycline 36 (72\%), Erythromycin 31 (62\%), Gentamycin 21 (42\%), Methicillin $29 \quad$ (58\%), Chloramphenicol 17 (34\%), Penicillin 38 (76\%), Tobramycin 26 (52\%), Norfloxacin 25 (50 \%), Nitrofurantoin 27 (54 \%) and Vancomycin 08 (16. \%) (Table 2) (Figure 1) The prevalence rate of methicillin resistance among 50 coagulase positive $S$. aureus isolates on disc diffusion was $58.00 \%$ as shown in Table 2. More than $50 \%$ of $\mathrm{S}$. aureus strains were found as resistance to most of the antibiotics. Vancomycin, amikacin, gentamycin, chloramphenicol and nrofloxacin were shown less resistance. These drugs are the good choice for the treatment of S. aureus infection. Simillar type of prevalence rate in Tata hospital in Mumbai ${ }^{9}$ where, it reached to 64\% in 1996.
In 2001 Vidhani et. al. found 51.6\% MRSA prevalence in New Delhi 10. The INSAR group ${ }^{11}$, India reported MRSA prevalence was 42\% in 2008 and $40 \%$ in 2009. According to Khan, et. al., study prevalence of MRSA 32\% in 201112. Tambekar, et. al, were reported high level of HA-MRSA in Vidarbha region ${ }^{13}$.

\section{CONCLUSION :}

From the present study it can be concluded that the increasing trend of antimicrobial resistance was observed in coagulase positive $S$. aureus strains. The prevalence rate in Chandrapur district region was found up to $58 \%$. Most of the antibiotics tested were shown resistance towards $S$. aureus isolates. But vancomycin, gentamycin, amikacin are the good choice for the treatment of $S$. aureus infections. The regular surveillance of hospital acquired infection and implementation of strict antibiotic policy may be helpful for reducing the prevalence of MRSA infection.

\section{REFERENCE :}

Chakraborty, SP., Pramanik, P., and Roy, S. Emergence of antibiotic resistant Staphylococcus aureus and role of chitosan nanoparticles in drug delivery. Int J. Life Science \& Pharma Research, 2012; 2(1):96-115.

File, TM. Methicillin-resistant Staphylococcus aureus (MRSA): Focus on community associated MRSA. South African Journal of Epidemiology and Infection, 2008; 23:13-15.

Ben-David, D., Mermel, L. and Parenteau, S. Methicillin-resistant Staphylococcus aureus transmission: The possible importance of unrecognized healthcare worker carriage. American Journal of Infection Control, 2008; 36:93-97.

Ho, PL., Chuang, SK. and Choi, YF. Community associated Methicillinresistant and Methicillin sensitive Staphylococcus aureus: skin and soft tissue infections in Hong Kong. Diagnostic Microbiology and Infectious Disease, 2008; 61:245-50. 
Skinner, D. and Keefer, CS. Significance of bacteremia caused by Staphylococcus aureus. Archives of Internal Medicine. $1941 ; 68: 851-75$.

Green, BN., Johnson, CD., Egan, JT., et al. Methicillin-resistant Staphylococcus aureus: an overview for manual therapists. Journal of Chiropractic Medicine. 2012; 11:64-76.

Cosgrove, SE. and Carmeli, Y. The impact of antimicrobial resistance on health and economic outcomes. Clin. Infect Dis. 2003; 36:1433-7.

CLSI (2006): Performance standards of antimicrobial susceptibility testing, Fifteenth International supplement, CLSI document M 100-S16, Vol. 26-3; M7-A7, Vol.26-2; M2-A9, Vol. 26-1. Wayne, PA. USA.

Mehta, A., Rodrigues, C., Kumar, et al. A pilot programme of MRSA surveillance in India. J. Postgraduate, Med., 1996;42:1-3.

Vidhani, S., Mehndiratta, PL. and Mathur, MD. Study of methicillin resistant $S$. aureus (MRSA)isolates from high risk patients. Indian Journal ofMedical Microbiology., 2001; 29:13-16.

Indian Network for Surveillance of Antimicrobial Resistance (INSAR) group, India Methicillin resistant Staphylococcus aureus (MRSA) in India: Prevalence \&susceptibility pattern. Indian J. Med. Res., 2013;137: 363-69.

Khan, F., Shukla, I., and Rivizi, M. The role of non-beta-lactum antimicrobial and screening for Vancomycin resistance in MRSA. Malaysian J. Microbiol, $201 ; 7: 66-70$.

Tambekar,DH., Dhanorkar, DV., Gulhane,SR. and Dudhane.MN. Prevalence and antimicrobial susceptibility pattern of methicillin resistant Staphylococcus aureus from healthcare and community associated sources. Afr. J. Infect. Dis., 1(1):5256.
Table 1: Coagulase positive and negative with number of samples of $S$. aureus in Chandrapur

\begin{tabular}{|l|l|l|l|}
\hline Sample & CoPSA & CoNSA & Total \\
\hline Pus & 27 & 12 & 39 \\
\hline Sputum & 08 & 05 & 13 \\
\hline $\begin{array}{l}\text { Burned } \\
\text { Wound }\end{array}$ & 15 & 11 & 26 \\
\hline Total & 50 & 28 & 78 \\
\hline
\end{tabular}

Table 2: Over all distribution of antimicrobial susceptibility of $S$. aureus on disc diffusion in Chandrapur (Total No. 50)

\begin{tabular}{|l|l|l|l|l|l|}
\hline \multirow{2}{*}{$\begin{array}{l}\text { Sr. } \\
\text { No }\end{array}$} & \multirow{2}{*}{ Name of Antibiotic } & \multicolumn{2}{l}{ Resistant } & \multicolumn{2}{l|}{ Sensitive } \\
\cline { 3 - 6 } & & $\begin{array}{l}\text { Res } \\
\text { ista } \\
\text { nt }\end{array}$ & $\%$ & $\begin{array}{l}\text { Sensi } \\
\text { tive }\end{array}$ & $\%$ \\
\hline 1. & Vancomycin (V) & 8 & 16 & 42 & 84 \\
\hline 2. & Oxacillin (Ox) & 29 & 58 & 21 & 42 \\
\hline 3. & Amikacin (Ak) & 12 & 24 & 38 & 76 \\
\hline 4. & Tetracycline (Te) & 36 & 72 & 14 & 28 \\
\hline 5. & Erythromycin (E) & 31 & 62 & 19 & 38 \\
\hline 6. & Gentamycin (GN) & 21 & 42 & 29 & 58 \\
\hline 7. & Methicillin (MET) & 29 & 58 & 21 & 42 \\
\hline 8. & Chloramphenicol (C) & 17 & 34 & 33 & 66 \\
\hline 9. & Penicillin (P) & 38 & 76 & 12 & 24 \\
\hline 10. & Tobramycin (TB) & 26 & 52 & 24 & 48 \\
\hline 11. & Norfloxacin (NX) & 25 & 50 & 25 & 50 \\
\hline 12. & Nitrofurantoin (NF) & 27 & 54 & 23 & 46 \\
\hline & & & & & \\
\hline
\end{tabular}




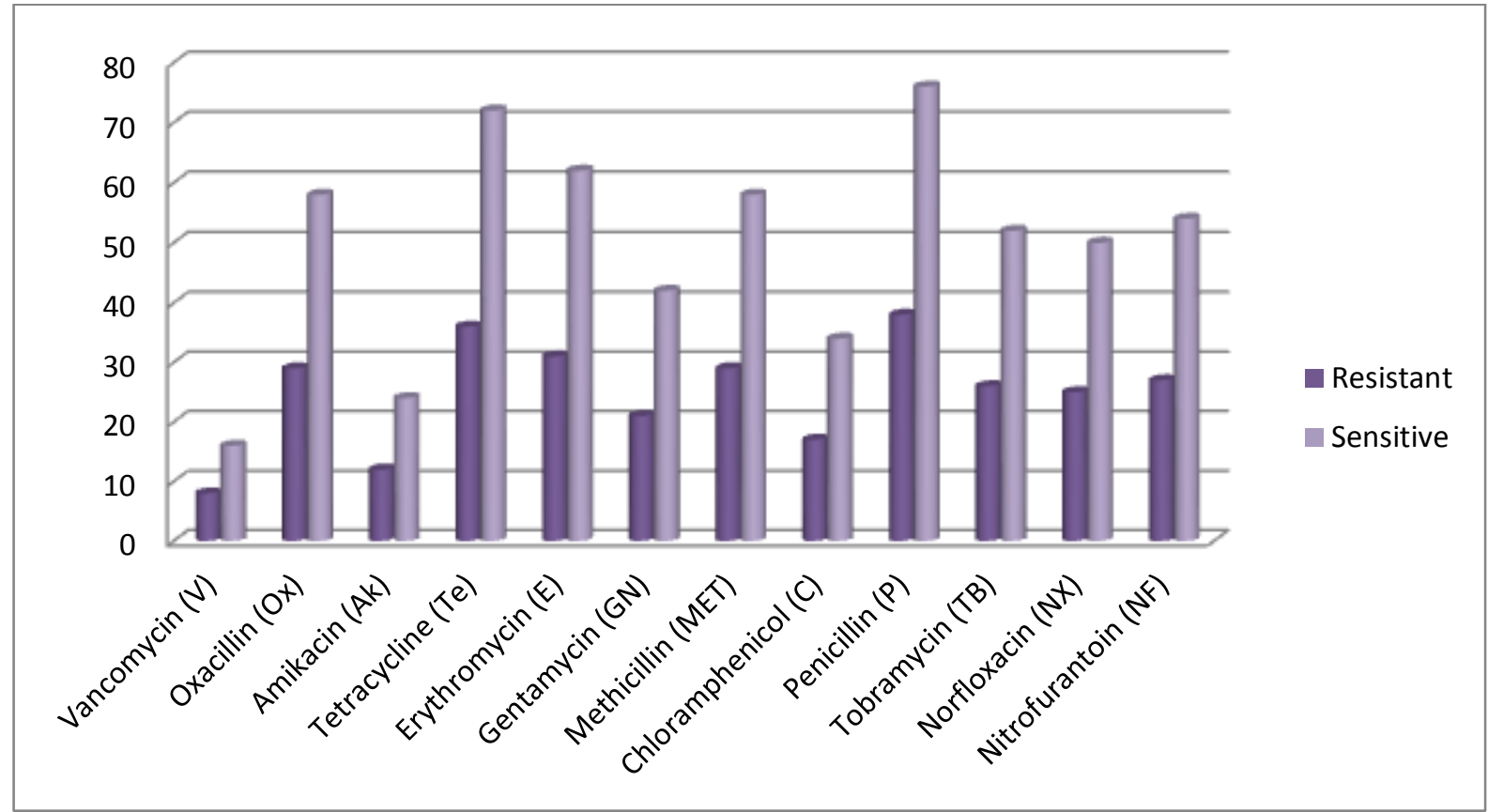

Figure 1 Overall distribution of antimicrobial susceptibility of $S$. aureus on disc diffusion in Gadchiroli 